\title{
Determination of methotrexate at a silver solid amalgam electrode by differential pulse voltammetry
}

Lenka Janíková-Bandžuchová and Renáta Šelešovská

\section{QUERY SHEET}

This page lists questions we have about your paper. The numbers displayed at left can be found in the text of the paper for reference. In addition, please review your paper as a whole for correctness.

Q1: Au: Citations [De Abreau, Ferraz, and Goulart 2002; Tian and Cronstein 2007] have been updated as per the reference list. OK?

Q2: $\mathrm{Au}$ : Provide a reference entry for Gurira et al. 1983 (cited twice in text).

Q3: Au: Please provide reference for citation [Ashbar 2013].

Q4: $\mathrm{Au}$ : Please confirm information provided in the Funding section is accurate.

Q5: Au: References [Gao et al. 2007; Tian and Cronstein 2007; Murad et al. 1993] have been updated. OK?.

Q6: Au: Please provide journal title for the reference [Ye et al. 2005].

\section{TABLE OF CONTENTS LISTING}

The table of contents for the journal will list your paper exactly as it appears below: 


\title{
ELECTROCHEMISTRY
}

\section{Determination of methotrexate at a silver solid amalgam electrode by differential pulse voltammetry}

\author{
Lenka Janíková-Bandžuchová and Renáta Šelešovská \\ Faculty of Chemical Technology, Institute of Environmental and Chemical Engineering, University of Pardubice, \\ Pardubice, Czech Republic
}

\begin{abstract}
An ultrasensitive voltammetric method is reported for the determination of methotrexate using a polished modified silver solid amalgam electrode. Electrochemical behavior of this compound was examined using cyclic, linear sweep, and differential pulse voltammetry. Methotrexate provided two reduction and one oxidation signal in acidic and neutral media. The first reduction peak ( $E_{\mathrm{p}}=-350$ millivolts vs. $\mathrm{Ag} \mid \mathrm{AgCl}$ electrode) and supporting electrolyte of $\mathrm{pH} 5$ was chosen for further experiments. Different pulse voltammetry parameters were optimized in combination with adsorptive stripping and the applicability of the method was verified. A low limit of detection $\left(1.5 \times 10^{-10}\right.$ moles per liter), good repeatability of determination (relative standard deviation $\geq 3.5 \%, n=5$ ), and good repeatability of measurements (relative standard deviation of $1.7 \%$ at $1.0 \times 10^{-7}$ mole per liter methotrexate and $n=11$ ) was obtained. The method was employed for the accurate determination of methotrexate in a chemotherapeutic preparation.
\end{abstract}

\section{ARTICLE HISTORY}

Received 21 November 2014

Accepted 28 November 2014

\section{KEYWORDS}

Chemotherapeutic drug; methotrexate; silver solid amalgam electrode; voltammetry

\section{Introduction}

Methotrexate is a compound based on the pteridine, which is used for its biological activity as a chemotherapeutic drug. It is often called antifolate, because methotrexate competitively inhibits the enzyme dihydrofolate reductase (E.C. 1.5.1.3.), which leads to disruption of the metabolism of folic acid and reduction of its biologically active derivative (e.g., tetrahydrofolates) concentration (Martínková et al. 2007; Devlin 2011). This effect is used for treatment of various diseases. Methotrexate has demonstrated effective antineoplastic activity and thus, it is used in the treatment of certain forms of cancer, psoriasis, rheumatoid arthritis, lupus, inflammatory bowel disease, and scleroderma (van den Hoogen, Boerbooms, and van de Putte 1989; Scully, Anderson, and Cannon 1991; Murad et al. 1993; Van Dooren-Greebe et al. 1994; Kuhn et al. 2002; Martínková et al. 2007; Saibeni et al. 2012). Methotrexate is less toxic than other chemotherapeutic drugs. Moreover, it is the only cytostatic, which has an antagonist, tetrahydrofolate leucovorin, which can minimize its side effects, and therefore it can be administrated at high dosage by a particular schedule (van den Hoogen, Boerbooms, and van de Putte 1989; Martínková et al. 2007; Devlin 2011; Saibeni et al. 2012).

Various methods for determination of methotrexate have developed due its biological significance. The most widely used analytical methods for its determination are liquid chromatography and highperformance liquid chromatography, respectively, with various detectors including ultraviolet-visible (Farid, Watson, and Stewart 1983; Aboleen, Simpson, and Backes 1996; Floridia et al. 1999; Turci, Micoli, and Minoia 2000), fluorimetry (Šalamoun and František 1986; McCrudden and Tett 1999; 
Merás, Mansilla, and Gómez 2005) and mass spectrometry (Turci, Micoli, and Minoia 2000; Koufopantelis et al. 2009; Rodin et al. 2013). Other techniques such as spectrophotometry (Sastry and Lingeswara Rao 1996), capillary zone electrophoresis (Flores et al. 2005), and immunoassays (Bore et al. 1984; Eksbors et al. 1996) have also been used for methotrexate determination.

Electrochemical methods present a good alternative to the above mentioned approaches. The main advantages are time and money saving analysis, low cost of instrumentation, high sensitivity, and miniature/portable analyzers. Moreover, electrochemistry allows investigation of the bioactive properties because many processes correlate to biological activities (De Abreau, Ferraz, and Goulart 2002).

Methotrexate is an electrochemically active compound and its polarographic and voltammetric behavior have been primarily studied at mercury electrodes. Asahi focused on its polarographic behavior using a dropping mercury electrode (DME) in 1959 (Asahi 1959). More than twenty years later, Gurira and Bowers clearly described electrochemical processes of methotrexate and its main metabolite 7-hydroxymetothrexate on the DME and hanging mercury drop electrode (HMDE) (Gurira and Bowers 1983, 1987). Afterward, several papers dealt with the voltammetric determination of methotrexate on mercury electrodes especially on the HMDE by cyclic voltammetry (CV), differential pulse voltammetry (DPV), (Ye et al. 2005) and adsorptive stripping differential pulse voltammetry (DPAdSV) (J. Wang et al. 1986; Cataldi et al. 1988). Ordieres et al. applied also a.c. polarography on the DME (Ordieres et al 1990).

Recently, some reports have been focused on the voltammetric determination of methotrexate using solid or paste working electrodes: carbon based (J. Wang et al. 1986; El-Hady et al. 2006; Gao et al. 2007; F. Wang et al. 2009; F. Wang et al. 2012; Zhu et al. 2013; Šelešovská, JaníkováBandžuchová, and Chýlková 2014) and bismuth film electrodes (Asbahr et al. 2013). The development of new electrode materials, which can compete or replace mercury, is a major goal of modern electroanalytical chemistry. However, mercury is still one of the most commonly used electrode materials due to its excellent electrochemical properties, e.g., high hydrogen overvoltage and renewal of the working surface after every analysis by a new drop. However, it has also some disadvantages such as poor mechanic stability and the toxicity of the liquid mercury (Barek et al. 2001). The silver solid amalgam electrode (AgSAE) represent an intermediate step between mercury and solid electrodes and combine their advantages (Novotný and Yosypchuk 2000; Barek et al. 2006; Yosypchuk and Barek 2009). Various types of AgSAE based on the modification of the working surface exist: polished (p-AgSAE), mercury meniscus modified (m-AgSAE), and mercury film modified (MF-AgSAE). The polished modification, which is used as a working electrode in the present paper, is a totally liquid mercury free modification of the AgSAE and it represents a "green" alternative to the mercury electrodes with similar electrochemical properties (Fadrná 2004). In recent years, our research group focused on the voltammetric analysis of bioactive compounds including folates (folic acid and leucovorin) or structurally similar compounds (methotrexate) with the m-AgSAE (Bandžuchová et al. 2011; Šelešovská, Bandžuchová, and Navrátil 2011; Šelešovská et al. 2012) and p-AgSAE (folic acid (Bandžuchová and Šelešovská 2011) and leucovorin (Šelešovská et al. 2012)), respectively. It was found, that AgSAEs represent a suitable alternative for voltammetric analysis of these compounds.

The voltammetric determination of methotrexate with liquid mercury free p-AgSAE is described in the present paper. The behavior of this bioactive compound was examined using various techniques and the applicability of optimized adsorptive stripping differential pulse voltammetry was investigated for the determination of methotrexate in a pharmaceutical preparation.

\section{Experimental}

\section{Chemicals}

All chemicals used for preparing of the standard solutions, supporting electrolytes and other stock solutions were of suitable purity and were used as obtained. All solutions were prepared in distilled water. Methotrexate (Lachema, Brno, Czech Republic) was dissolved in 0.01 mole per liter solution of 
$\mathrm{NaOH}$ (Lachema, Brno, Czech Republic) and was stored in the dark in a refrigerator. This solution was stable for several weeks and no changes of consistency or color were observed. The analyzed solutions were prepared by a dilution of the stock solution with distilled water daily. Britton-Robinson buffer of a $\mathrm{pH}$ value from 3.0 to 12.0 was prepared from an alkaline component of 0.2 mole per liter $\mathrm{NaOH}$ (Lachema, Brno, Czech Republic) and an acidic component consisting of $\mathrm{H}_{3} \mathrm{PO}_{4}, \mathrm{H}_{3} \mathrm{BO}_{3}$, and $\mathrm{H}_{3} \mathrm{COOH}$ (all Lachema, Brno, Czech Republic) of the same concentration (0.04 mole per liter). 0.05 mole per liter Acetate buffer was prepared by mixing 0.5 mole per liter sodium acetate and 0.5 mole per liter acetic acid (both Sigma Aldrich) and diluted with distilled water to the required concentration. A solution of 0.2 mole per liter $\mathrm{KCl}$ required for the activation of the working electrode was prepared by dissolving of a suitable amount of $\mathrm{KCl}$ (Lachema, Brno, Czech Republic) in distilled water.

\section{Instrumentation}

Voltammetric measurements were performed with a computer controlled Eco-Tribo Polarograph (Polaro-Sensors, Prague, Czech Republic) equipped with Polar.Pro software for Windows XP version 5.1. All experiments were carried out with a three electrode set up, where p-AgSAE with a working surface of 0.28 square millimeter (Eco-Trend Plus, Prague, Czech Republic) served as the working electrode, a $\mathrm{Ag}|\mathrm{AgCl}|$ saturated $\mathrm{KCl}$ electrode was the reference, and platinum wire was the auxiliary electrode (both from Monokrystaly, Turnov, Czech Republic). Oxygen was removed from the measured solution by bubbling with nitrogen (purity class 4.0; Linde, Prague, Czech Republic) for five minutes. The values of $\mathrm{pH}$ were measured using a Hanna 221 (Hanna Instruments, USA) and standard solutions of methotrexate were prepared using an ultrasonic bath Bandelin Sonorex (Schalltec, Germany). All measurements were performed at a laboratory temperature $\left(23 \pm 2^{\circ} \mathrm{C}\right)$.

\section{Voltammetric measurements}

The voltammetric behavior of methotrexate was investigated by cyclic voltammetry $(\mathrm{CV})$ at an initial potential $\left(E_{\text {in }}\right)$ of 0 millivolt, switching potential $\left(E_{\text {switch }}\right)$ of -1300 millivolts, and a scan rate $(v)$ of 100 millivolts per second. The influence of $\mathrm{pH}$ on the compound was also investigated. Linear sweep voltammetry (LSV) with $E_{\text {in }}=0$ millivolt, $E_{\text {fin }}=-1000$ millivolts and $v=100$ millivolts per second was applied for an influence of a scan rate. Adsorptive stripping differential pulse voltammetry with $E_{\text {in }}=0$ millivolt, $E_{\text {fin }}=-1000$ millivolts, pulse width of 80 milliseconds, pulse height of -50 millivolts, $v=20$ millivolts per second, potential of accumulation of 0 millivolt, and thirty regeneration cycles between 0 and -1600 millivolts was used for the determination of methotrexate. The accumulation time depended on the concentration of methotrexate in the analyzed solution. 0.05 mole per liter Acetate buffer $(\mathrm{pH} \mathrm{5)}$ was used as the supporting electrolyte for measurements. Purified nitrogen was passed through the solution for five minutes prior to measurements and was maintained above the solution in the cell. All peaks were evaluated from the straight line connecting the minima before and after the peak. The displayed curves were not baseline corrected.

The limits of decision, detection, and quantification were calculated using the $\mathrm{K}^{\star}$ Sigma method (Miller and Miller 2005) and the parameters of calibration curves (e.g., slope, intercept) were calculated using Excel 2010 (Microsoft, USA).

\section{Preparation of silver solid amalgam electrode}

A silver solid amalgam electrode was abraded on a soft emery-paper and polished using a kit (Electrochemické detektory s.r.o., Turnov, Czech Republic) consisting of a polyurethane pad, $\mathrm{Al}_{2} \mathrm{O}_{3}$ suspension (particle size 1.1 micrometer), and soft polishing $\mathrm{Al}_{2} \mathrm{O}_{3}$ powder (particle size 0.3 micrometer). It is suitable to polish the working surface once per week in the case of long term measurements. Prior to beginning work, as well as after every pause longer than one hour, the electrode surface was activated in a solution of 0.2 mole per liter $\mathrm{KCl}$ by applying -2200 millivolts 
vs. the $\mathrm{Ag}|\mathrm{AgCl}|$ saturated $\mathrm{KCl}$ electrode for five minutes with stirring. The regeneration step of the electrode surface was incorporated into Polar 5.1 software method. The optimal process consisted of thirty regeneration cycles between 0 and -1600 millivolts (the limiting potentials were kept for 0.3 second) in the analyzed medium.

\section{Sample preparation}

One tablet of the pharmaceutical preparation (2.500 milligrams methotrexate per tablet) was powdered in a mortar, quantitatively dissolved in 100 milliters of 0.01 mole per liter $\mathrm{NaOH}$ with sonication, and filtered. A 9 microliters aliquot of the clear filtrate was diluted with supporting electrolyte to 10 milliliters. Based on the label, the methotrexate concentration in the solution was $5 \times 10^{-8}$ moles per liter. The concentration of methotrexate was evaluated by the method of standard addition.

\section{Results and discussion}

\section{Effect of supporting electrolyte}

The choice of supporting electrolyte is essential for the optimization process. The influence of $\mathrm{pH}$ of the supporting electrolyte on the voltammetric behavior of $1 \times 10^{-5}$ mole per liter methotrexate was examined using cyclic voltammetry in Britton-Robinson buffer ( $\mathrm{pH}$ from 3.0 to 12.0). Methotrexate provided two reduction (cathodic) signals $\left(E_{\mathrm{p} 1}=-350\right.$ millivolts, $E_{\mathrm{p} 2}=-760$ millivolts in medium of $\mathrm{pH} 5$ ) in acidic and neutral solutions. At $\mathrm{pH}$ values above 7 , the second peak rapidly decreased and disappeared. Only one oxidation (anodic) signal $\left(E_{\mathrm{p} 1}=-320\right.$ millivolts; $\left.\mathrm{pH} 5\right)$ was recorded over the tested $\mathrm{pH}$ range. A reversible electrode process is proposed by the difference of 21 millivolts between the positions of the first reduction and the oxidation peak. Example cyclic voltammograms of methotrexate at $\mathrm{pH} 5$ and $\mathrm{pH} 8$ are shown in Figure 1. The third reduction peak observed on mercury electrodes (Gurira et al. 1983) or electrodes with mercury surface (Šelešovská, Bandžuchová, and Navrátil 2011) were not recorded due to the narrower potential window of p-AgSAE. This peak also probably overlapped a signal from the decomposition of the supporting electrolyte.

The height and the position of reduction signals were strongly dependent on $\mathrm{pH}$. The highest current response of peak 1, which was selected for further analytical examination due to its good shape and evaluability, was recorded at $\mathrm{pH} 5$ (Figure 2). Therefore, media of $\mathrm{pH} 5$ - Britton-Robinson buffer and 0.05 mole per liter acetate buffer were chosen for further examination. It was ascertained that the reduction peak was more stable and intense in the acetate buffer, which was used as the supporting electrolyte for all subsequent experiments. The positions of the reduction signals also varied with $\mathrm{pH}$. The peaks moved linearly to more negative potentials with increasing $\mathrm{pH}$. This shift

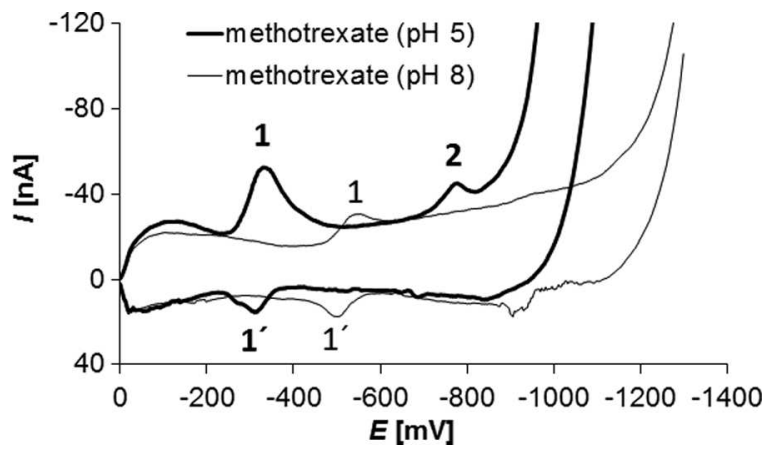

Figure 1. Cyclic voltammogram of $1 \times 10^{-5}$ mole per liter methotrexate in Britton-Robinson buffer at pH 5 (bold line) and of pH 8 (thin line) on the polished silver solid amalgam electrode. Conditions: $E_{\mathrm{in}}=0$ millivolt, $E_{\mathrm{switch}}=-1300$ millivolts, $\nu=100$ millivolts per second. 


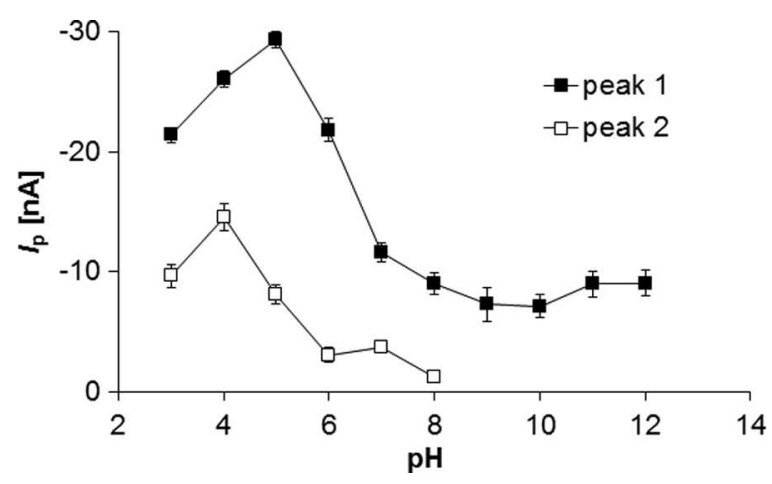

Figure 2. Cyclic voltammetric dependence of peak height $\left(I_{\mathrm{p}}\right)$ on the $\mathrm{pH}$ value of supporting electrolyte. Conditions: $E_{\text {in }}=0$ millivolt, $E_{\text {switch }}=-1300$ millivolts, $\nu=100$ millivolts per second.

shows that protons participate in the reduction processes on the p-AgSAE. This dependence is linear over the entire studied $\mathrm{pH}$ range (peak 1) and 3 to 8 (peak 2), respectively. The slopes [-62.9 millivolts (peak 1) and -62.3 millivolts (peak 2)] were very close to the theoretical value from the Nernst equation ( -59.2 millivolts), which corresponded to a mechanism involving the same number of electrons and protons. It can be assumed that the electrode processes on the p-AgSAE involved two electrons and two protons in neutral and acidic media with simple reduction in alkaline solutions as reported by Gurira et al. (1983) on mercury.

\section{Effect of scan rate}

Useful information including the electrochemical mechanism (rate-limiting step) may be observed from the dependence of the peak current on the scan rate. The effect of the scan rate $(v)$ on the voltammetric behavior of $5 \times 10^{-6}$ moles per liter methotrexate was examined employing linear sweep voltammetry from 10 to 300 millivolts per second. Peak 1 increased linearly with the scan rate and this dependence was approximated by equation (1) with a coefficient of determination $R^{2}=0.9974$. This result suggested an adsorption-control electrode process. The " $\log \left(I_{\mathrm{p}}\right)-\log (v)$ " analysis was applied for elucidation of controlling processes of the reduction as well. A linear dependence was obtained. Nevertheless, the slope of the equation $k=(0.8770 \pm 0.0079)$ was not equal 1 or 0.5 with $p \leq 0.05$. Therefore, it can be assumed that the investigated process is more complicated and cannot be characterized as only adsorption controlled only or only diffusion controlled.

$$
I_{\mathrm{p}}[\mathrm{nA}]=(-0.210 \pm 0.012) v\left[\mathrm{mV} \mathrm{s}^{-1}\right]-3.3 \pm 1.2
$$

\section{Analytical figures of merit}

Adsorptive stripping differential pulse voltammetry is an effective electrochemical technique, which has already been applied for analysis of numerous biologically active compounds. Accordingly, potential of accumulation $\left(E_{\text {acc }}\right)$, time of accumulation $\left(t_{\text {acc }}\right)$, and parameters of electrochemical regeneration of the p-AgSAE working surface were examined in order to optimize conditions for the determination of methotrexate. All experiments (except investigations of accumulation time) were carried out at $1 \times 10^{-7}$ mole per liter methotrexate in 0.05 mole per liter acetate buffer.

It was necessary to optimize the parameters of the regeneration process to ensure the reproducibility of the current on the p-AgSAE. The regeneration step was inserted directly into the controlling software before every analysis in the analyzed solution. Two mechanisms of the surface regeneration were tested: application of a constant negative potential for a given time and a few tens of polarizing cycles, respectively. The second mechanism proved more efficient for the regeneration of the electrode 
surface. The optimal regeneration process included the application of thirty cycles between -1600 millivolts and 0 millivolt, when the limiting potentials were maintained at $t_{\text {reg }}=0.3$ second. The efficiency of the surface regeneration was confirmed by repeated measurements and the relative standard deviation (RSD) of eleven repeated measurements on the same p-AgSAE surface was $1.68 \%$. This value was comparable with that obtained on the HMDE (Šelešovská, Bandžuchová, and Navrátil 2011) where the surface regeneration was realized by the new mercury drop. The relative standard deviation of eleven repeated measurements of $1 \times 10^{-7}$ mole per liter methotrexate measured on the HMDE was $1.75 \%$. These results show that the regeneration process was highly efficient for methotrexate on the p-AgSAE.

As the reduction of methotrexate is partly influenced by adsorption, this biomolecule may be adsorbed on the surface at a suitable accumulation potential. Thus, the effect of the accumulation potential on the response of methotrexate was varied from 0 to -600 millivolts at a constant accumulation time (ten seconds). The highest response was found at 0 millivolt and lower accumulation potentials reduced the response. Thereby, this value was employed in subsequent experiments. The possibility of preconcentration and thus increasing sensitivity of the method was also confirmed, as when the accumulation time was extended, the peak increased linearly up to forty seconds (Figure 3). Equation (2) describes the linear dependence between the response of $1 \times 10^{-7}$ mole per liter methotrexate and accumulation time from zero to forty seconds (the inset of Figure 3). Longer times resulted in a decreased growth of the current response and a limiting value at approximately sixty seconds. A suitable accumulation time was optimized for every concentration of methotrexate.

$$
I_{\mathrm{p}}[\mathrm{nA}]=(-0.181 \pm 0.010) t_{\mathrm{acc}}[\mathrm{s}]-2.69 \pm 0.28, R^{2}=0.9970
$$

The optimized differential pulse voltammetry conditions were applied for the determination of methotrexate. The obtained results are summarized in Table 1, showing good accuracy. The concentration dependence of $1 \times 10^{-8}$ to $7 \times 10^{-8}$ moles per liter methotrexate on the p-AgSAE is shown in Figure 4 . The inset of Figure 4 shows that the peak current increased linearly with methotrexate concentration as described by EQ3. The linear dynamic range was from $5 \times 10^{-10}$ to $3 \times 10^{-6}$ moles per liter. Due to the use of various accumulation times, it was not possible to measure this dependence in one analysis.

$$
I_{\mathrm{p}}[\mathrm{nA}]=(-0.0640 \pm 0.0011) c[\mathrm{nmol} \mathrm{L}-1]-0.0570, R^{2}=0.9997
$$

Other statistical parameters including the limit of decision, limit of detection, and limit of quantification were determined to be $8.0 \times 10^{-11}, 1.5 \times 10^{-10}$, and $2.2 \times 10^{-10}$ moles per liter, respectively. The low limit of detection confirms the high sensitivity of the method.

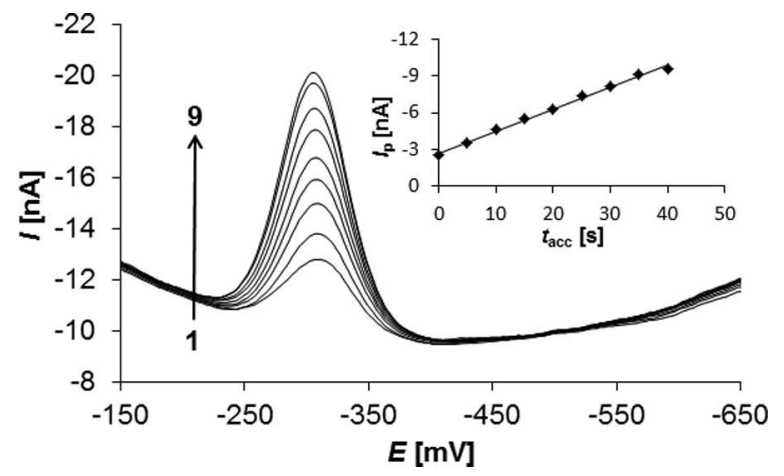

Figure 3. Adsorptive stripping differential pulse voltammograms of $1 \times 10^{-7}$ mole per liter methotrexate measured at various accumulation times: (1) $0,(2) 5,(3) 10,(4) 15,(5) 20,(6) 25,(7) 30,(8) 35$, and (9) 40 seconds on the polished silver solid amalgam electrode. Inset: Dependence of the peak height $\left(I_{\mathrm{p}}\right)$ on the accumulation time (tacc). Conditions: $E_{\text {in }}=0$ millivolt, $E_{\text {fin }}=-1000$ millivolts, pulse width of 80 milliseconds, pulse height of -50 millivolts, $\nu=20$ millivolts per second, $E_{\text {acc }}=0$ millivolt, $t_{\mathrm{acc}}=0-40$ seconds, no. of regeneration cycles thirty, $E_{\mathrm{reg} 1}=0$ millivolt, $E_{\mathrm{reg} 2}=-1600$ millivolts, $t_{\mathrm{reg} 1,2}=0.3$ second. 
Table 1. Determination of methotrexate in standards.

\begin{tabular}{llrc}
\hline Added (mole per liter) & Found (mole per liter) & Recovery (\%) & Relative standard deviation(\%) \\
\hline $1.000 \times 10^{-8}$ & $(1.001 \pm 0.010) \times 10^{-8}$ & $99.1-101.1$ & 1.9 \\
$5.000 \times 10^{-9}$ & $(4.990 \pm 0.120) \times 10^{-9}$ & $97.4-102.2$ & 0.4 \\
$1.000 \times 10^{-9}$ & $(1.020 \pm 0.020) \times 10^{-9}$ & $100.0-104.0$ & 3.4 \\
\hline
\end{tabular}

Methotrexate is primarily excreted unchanged in urine (Tian and Cronstein 2007) but this matrix contains also high concentrations of folates that have similar structure as methotrexate and thus may be potential interferents. Folic acid and folates provided similar voltammetric response as methotrexate and therefore methotrexate was not determined accurately in their presence. Therefore, separation is required before determination in urine and, consequently, no further interference studies were performed.

\section{Comparison with other voltammetric methods}

On the basis of a literature survey, the mercury electrodes (J. Wang et al. 1986, Cataldi et al. 1988, Ordieres et al. 1990; Ye et al. 2005; Šelešovská, Bandžuchová, and Navrátil 2011), carbon based working electrodes (J. Wang et al. 1986; El-Hady et al. 2006; Gao et al. 2007; F. Wang et al. 2009; F. Wang et al. 2012; Zhu et al. 2013) and bismuth film electrode (Asbahr et al. 2013), respectively, have been successfully applied for the voltammetric determination of this chemotherapeutic. Our research group also reported the use of the m-AgSAE (Šelešovská, Bandžuchová, and Navrátil 2011) and boron-doped diamond electrode (Šelešovská, Janíková-Bandžuchová, and Chýlková 2014). A comparison between the analytical performance of this method and other electrochemical methods for determination of methotrexate is summarized in Table 2. The combination of the p-AgSAE and adsorptive stripping differential pulse voltammetry provides the lowest limit of detection. Moreover, $\mathrm{p}$-AgSAE is made from a non-toxic silver amalgam and does not contain liquid mercury (Fadrná 2004). It is also mechanically and chemically stable and its preparation and pretreatment is simple and time saving in comparison with the working electrodes described in the literature (F. Wang et al. 2009; F. Wang et al. 2012; Zhu et al. 2013). These results confirm the excellent electrochemical properties of the $\mathrm{p}$-AgSAE for the determination of methotrexate.

\section{Analysis of a pharmaceutical preparation}

The applicability of proposed method was verified by the analysis of a pharmaceutical preparation with declared content of methotrexate of 2.500 milligrams per tablet. The sample solution was

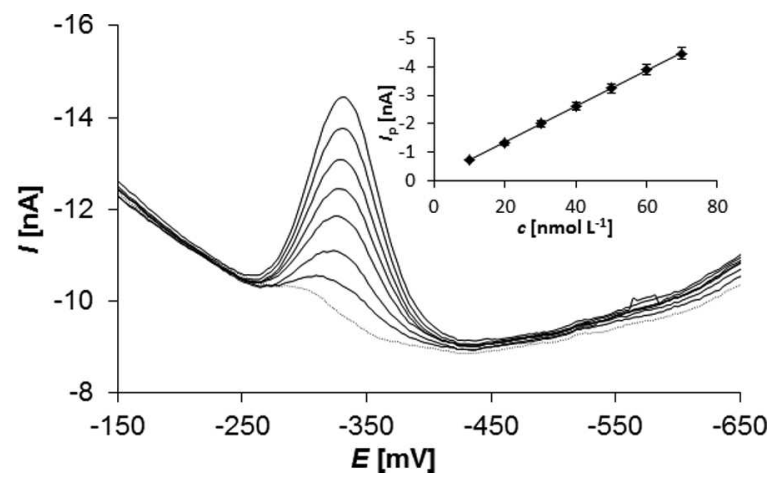

Figure 4. Adsorptive stripping differential pulse voltammograms in (1) absence and presence of methotrexate at various concentrations levels: (2) $1 \times 10^{-8}$, (3) $2 \times 10^{-8}$, (4) $3 \times 10^{-8}$, (5) $4 \times 10^{-8}$, (6) $5 \times 10^{-8}$, (7) $6 \times 10^{-8}$, and (8) $7 \times 10^{-8} \mathrm{moles}$ per liter on the polished silver solid amalgam electrode. Inset: Dependence of the peak height $\left(I_{\mathrm{p}}\right)$ on the concentration of methotrexate (c). Conditions: $E_{\text {in }}=0$ millivolt, $E_{\text {fin }}=-1000$ millivolts, pulse width of 80 milliseconds, pulse height of -50 millivolts, $v=20$ millivolts per second, $E_{\mathrm{acc}}=0$ millivolt, $t_{\mathrm{acc}}=20$ seconds, no. of regeneration cycles thirty, $E_{\mathrm{reg} 1}=0$ millivolt, $E_{\mathrm{reg} 2}=-1600$ millivolts, $t_{\text {reg } 1,2}=0.3$ second. 


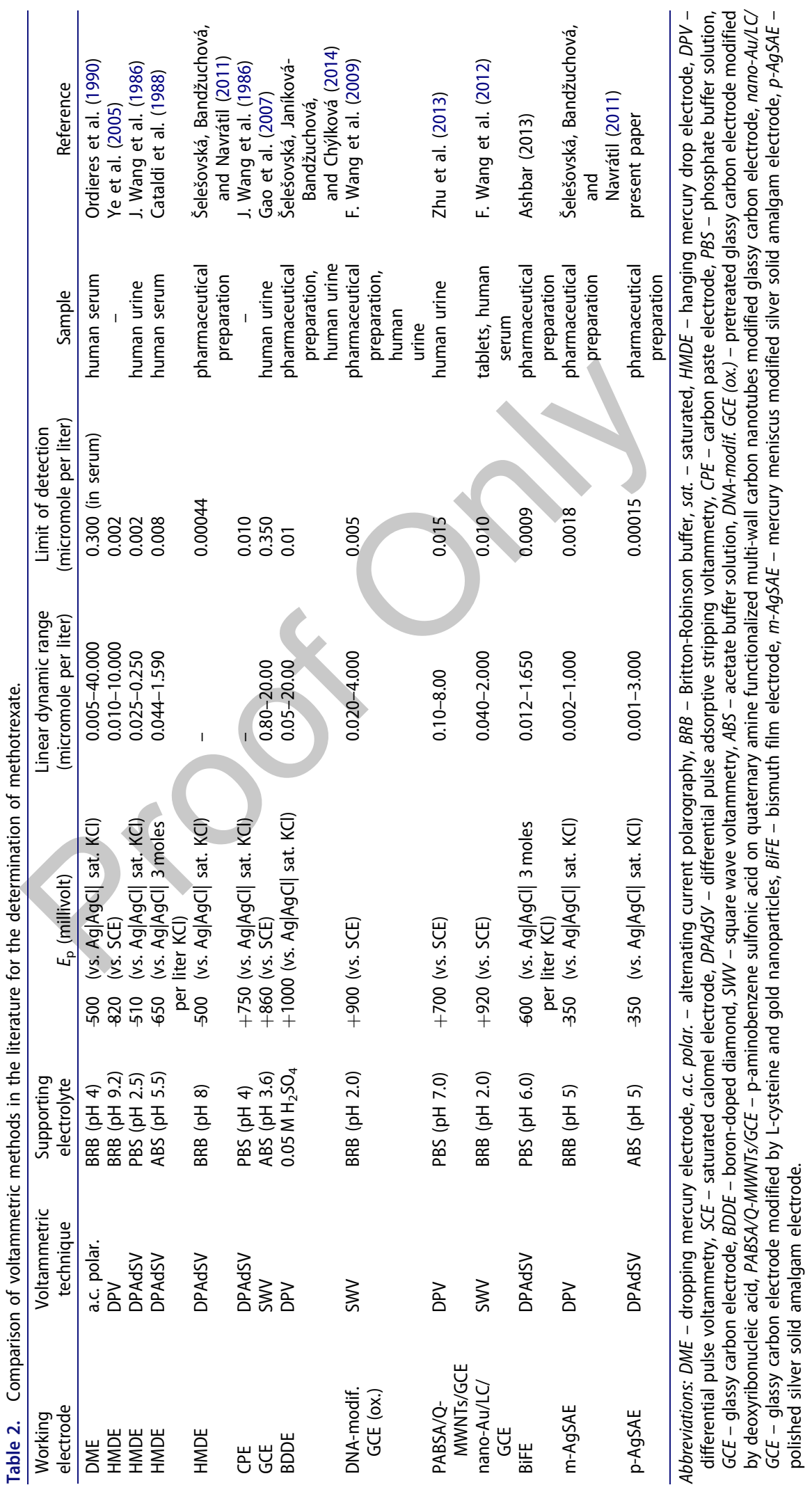




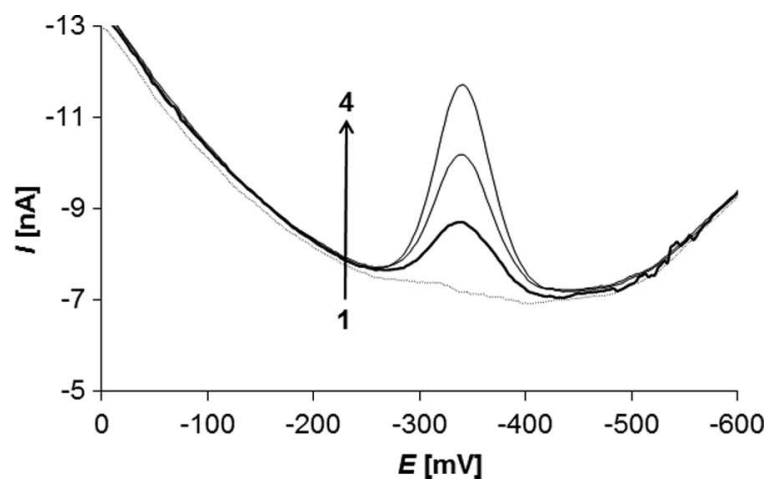

Figure 5. Adsorptive stripping differential pulse voltammograms of methotrexate in a pharmaceutical preparation on the polished silver solid amalgam electrode: (1) supporting electrolyte, (2) addition of the sample solution (9 microliters of sample with a methotrexate concentration of $5.6 \times 10^{-5}$ mole per liter), (3) standard addition of 50 microliters of $1.0 \times 10^{-5}$ mole per liter methotrexate, and (4) standard addition of 100 microliters of $1.0 \times 10^{-5}$ mole per liter methotrexate. Conditions: $E_{\text {in }}=0$ millivolt, $E_{\text {fin }}=-1000$ millivolts, pulse width of 80 milliseconds, pulse height of -50 millivolts, $\nu=20$ millivolts per second, $E_{\text {acc }}=0$ millivolt, $t_{\mathrm{acc}}=5$ seconds, no. of regeneration cycles thirty, $E_{\mathrm{reg} 1}=0$ millivolt, $E_{\mathrm{reg} 2}=-1600$ millivolts, $t_{\mathrm{reg} 1,2}=0.3$ second.

prepared as described above using the method of standard addition. The determined content was $(2.499 \pm 0.012) \mathrm{mg} /$ tablet $(99.48-100.44 \%$ recovery $)$ as the average of five replicates with a relative standard deviation of $0.7 \%$. These results demonstrate an accurate and precise determination. An example of a voltammogram is provided in Figure 5.

\section{Conclusions}

A polished silver solid amalgam electrode was used for the voltammetric determination of methotrexate. It was shown that this working electrode in combination with differential pulse voltammetry provided suitable determination of this bioactive compound. The sensitivity was increased by the insertion of an accumulation step before analysis to rapidly determine nanomolar amounts of methotrexate. The obtained limit of detection is lower or fully comparable with those previously described in the literature. Thereby, it can be concluded that the reported method is an effective, sensitive, and environmentally acceptable tool for the determination of methotrexate and other folates.

\section{Acknowledgement}

This work was supported by The Ministry of Education, Youth, and Sports of the Czech Republic (project No. CZ.1.07/2.3.00/30.0021).

\section{References}

Aboleen, H., J. Simpson, and D. Backes. 1996. Determination of methotrexate in serum by high-performance liquid chromatography. Journal of Chromatography B: Biomedical Sciences and Applications 681: 317-22. doi:10.1016/ 0378-4347(95)00580-3

Asahi, Y. 1959. Polarographic studies of pharmaceuticals. xv. polarography of pteridine derivatives. (v). aminopterin, pteroic acid, 10-formylpteroylglutamic acid, and a-methopterin. Yakugaku Zasshi 79: 1570-73. doi:NODOI

Asbahr, D., L. C. S. Figueiredo-Filho, F. C. Vincentini, G. G. Oliveira, O. Fatibello-Filho, and C. E. Banks. 2013. Differential pulse adsorptive stripping voltammetric determination of nanomolar levels of methotrexate utilizing bismuth film modified electrodes. Sensors and Actuators B: Chemical 188: 334-39. doi:10.1016/j.snb.2013.07.027

Bandžuchová, L., and R. Šelešovská. 2011. Voltammetric determination of folic acid using liquid mercury free silver amalgam electrode. Acta Chimica Slovenica 58: 776-84.

Bandžuchová, L., R. Šelešovská, T. Navrátil, and J. Chýlková. 2011. Electrochemical behavior of folic acid on mercury meniscus modified silver solid amalgam electrode. Electrochimica Acta 56: 2411-19. doi:10.1016/j.electacta. 2010.10.090 
Barek, J., J. Fischer, T. Navrátil, K. Pecková, and B. Yosypchuk. 2006. Silver solid amalgam electrodes as sensors for chemical carcinogens. Biosensors 6: 445-52. doi:10.3390/s6040445

Barek, J., A. G. Fogg, A. Muck, and J. Zima. 2001. Polarography and voltammetry at mercury electrodes. Critical Reviews in Analytical Chemistry 31: 291-309. doi:10.1080/20014091076776

Bore, P., R. Rahmani, J.-P. Cano, S. Just, and J. Barbet. 1984. Radioimmunoassays of 7-hydroxymethotrexate and methotrexate. Clinica Chimica Acta 141: 135-49. doi:10.1016/0009-8981(84)90006-8

Cataldi, T. R. I., A. Guerrieri, F. Palmisano, and P. G. Zambonin. 1988. Adsorptive cathodic stripping voltammetry of amethopterine at a static mercury drop electrode and its application to serum drug determination. Analyst 113: 869-73. doi:10.1039/an9881300869

De Abreau, F. C., P. A. L. Ferraz, and M. O. F. Goulart. 2002. Some applications of electrochemistry in biomedical chemistry. Emphasis on the correlation of electrochemical and bioactive properties. Journal of the Brazilian Chemical Society. 13: 19-35. doi:10.1590/s0103-50532002000100004

Devlin, T. M. (Ed.). 2011. Textbook of biochemistry: With clinical correlation. Hoboken, NJ: Wiley.

Eksbors, S., F. Albertioni, C. Rask, O. Beck, C. Palm, H. Schroeder, and C. Peterson. 1996. Methotrexate plasma pharmacokinetics: importance of assay method. Cancer Letters 108: 163-69. doi:10.1016/S0304-3835(96)04394-7

El-Hady, D. A., M. M. Seliem, R. Gotti, and N. A. El-Maali. 2006. Novel voltammetric method for enantioseparation of racemic methotrexate. Determination of its enantiomeric purity in some pharmaceuticals. Sensors and Actuatuors B: Chemical 113: 978-88.

Fadrná, R. 2004. Polished silver solid amalgam electrode: further characterization and applications in voltammetric measurements. Analytical Letters 37: 3255-70. doi:10.1081/al-200040338

Farid, Y. Y. Z., I. D. Watson, and M. J. Stewart. 1983. An assay for methotrexate and its metabolites in serum and urine by ion-pair high-performance liquid chromatography. Journal of Pharmaceutical and Biomedical Analysis 1: 55-63. doi:10.1016/0731-7085(83)80008-9

Flores, J. R., G. C. Penalvo, A. E. Mansilla, and M. J. R. Gómez. 2005. Capillary electrophoretic determination of methotrexate, leucovorin and folic acid in human urine. Journal of Chromatography B 819: 141-47. doi:10.1016/j.jchromb.2005.01.039

Floridia, L., A. M. Pietropaolo, M. Tavazzani, F. M. Rubino, and A. Colombi. 1999. High-performance liquid chromatography of methotrexate for environmental monitoring of surface contamination in hospital departments and assessment of occupational exposure. Journal of Chromatography B: Biomedical Sciences and Applications 726: 95-103. doi:10.1016/s0378-4347(98)00561-1

Gao, L., Z. Wu, J. Liu, and B. Ye. 2007. Anodic voltammetric behaviors of methotrexate at a glassy carbon electrode and its determination in spiked human urine. Journal of Electroanalytical Chemistry 610: 131-36. doi:10.1016/j. jelechem.2007.07.030

Gurira, R. C., and L. D. Bowers. 1983. Electrochemistry of methotrexate Part I. Characteristics of reduction. Journal of Electroanalytical Chemistry and Interfacial Electrochemistry 146: 109-22. doi:10.1016/S0022-0728(83)80115-6

Gurira, R. C., and L. D. Bowers. 1987. Electrochemistry of methotrexate and its metabolites Part II. Reduction of 7-hydroxymethotrexate. Journal of Electroanalytical Chemistry 220: 323-32.

Koufopantelis, P., S. Georgakakou, M. Kazanis, C. Giaginis, A. Margeli, S. Papargiri, and I. Panderi. 2009. Direct injection liquid chromatography/positive ion electrospray ionization mass spectrometric quantification of methotrexate, folinic acid, folic acid and ondansetron in human serum. Journal of Chromatography B 877: 3850-56. doi:10.1016/j.jchromb.2009.09.034

Kuhn, A., C. Specker, T. Ruzicka, and P. Lehman. 2002. Methotrexate treatment for refractory subacute cutaneous lupus erythematosus. Journal of the American Academy of Dermatology 46: 600-4. doi:10.1067/mjd.2002.114608

Martínková, J., J. Chládek, S. Mičuda, and J. Chládková. 2007. Pharmacology for medical students (in Czech). Prague, Czech Republic: Grada.

McCrudden, E. A., and S. E. Tett. 1999. Improved high-performance liquid chromatography determination of methotrexate and its major metabolite in plasma using a poly(styrene-divinylbenzene) column. Journal of Chromatography B: Biomedical Sciences and Applications 721: 87-92. doi:10.1016/s0378-4347(98)00439-3

Merás, I. D., A. E. Mansilla, and M. J. R. Gómez. 2005. Determination of methotrexate, several pteridines, and creatinine in human urine, previous oxidation with potassium permanganate, using HPLC with photometric and fluorimetric serial detection. Analytical Biochemistry 346: 201-9. doi:10.1016/j.ab.2005.07.038

Miller, J. N., and J. C. Miller. 2005. Statistics and chemometrics for analytical chemistry. Harlow, UK: Person Education.

Murad, A. M., F. F. Santiago, A. Petroianu, P. R. S. Rocha, M. A. G. Rodrigues, and M. Rausch. 1993. Modified therapy with 5-fluorouracil, doxorubicin, and methotrexate in advanced gastric cancer. Cancer 72: 37-41. doi:10.1002/ 1097-0142(19930701)72:1<37::AID-CNCR2820720109>3.0.CO;2-P

Novotný, L., and B. Yosypchuk. 2000. Solid silver amalgam electrode (in Czech). Chemické Listy 94: 1118-20.

Ordieres, A. J. M., A. C. Garcia, J. M. F. Alvarez, and P. T. Blanco. 1990. Phase-selective alternating current polarographic assay of methotrexate in human serum. Analytica Chimica Acta 233: 281-87. doi:10.1016/S0003-2670(00)83489-3

Rodin, I., A. Braun, A. Stavrianidi, and O. Shpigun. 2013. A validated LC-MS/MS method for rapid determination of methotrexate in human saliva and its application to an excretion evaluation study. Journal of Chromatography B 937: 1-6. doi:10.1016/j.jchromb.2013.07.026 
Saibeni, S., S. Bollani, A. Losco, A. Michielan, R. Sostegni, M. Devani, G. Lupinacci, et al. 2012. The use of methotrexate for treatment of inflammatory bowel disease in clinical practice. Digest. Digestive and Liver Disease 44: 123-27. doi:10.1016/j.dld.2011.09.015

Šalamoun, J., and J. František. 1986. Determination of methotrexate and its metabolites 7-hydroxymethotrexate and 2,4-diamino-N10-methylpteroic acid in biological fluids by liquid chromatography with fluorimetric detection. Journal of Chromatography B: Biomedical Sciences and Applications 378: 173-81. doi:10.1016/s0378-4347(00) 80710-0

Sastry, C. S. P., and J. S. V. M. Lingeswara Rao. 1996. Spectrophotometric methods for the determination of methotrexate in pharmaceutical formulations. Anal. AARN News Letter 29: 1763-78. doi:10.1080/00032719608001522

Scully, C. J., C. J. Anderson, and G. W. Cannon. 1991. Long-term methotrexate therapy for rheumatoid arthritis. Seminars in Arthritis and Rheumatism 20: 317-31. doi:10.1016/0049-0172(91)90032-u

Šelešovská, R., L. Bandžuchová, and T. Navrátil. 2011. Voltammetric behavior of methotrexate using mercury meniscus modified silver solid amalgam electrode. Electroanalysis 23: 177-87. doi:10.1002/elan.201000440

Šelešovská, R., L. Bandžuchová, T. Navrátil, and J. Chýlková. 2012. Voltammetric determination of leucovorin using silver solid amalgam electrode. Electrochimica Acta 60: 375-83. doi:10.1016/j.electacta.2011.11.071

Šelešovská, R., L. Janíková-Bandžuchová, and J. Chýlková. 2014. Sensitive voltammetric sensor based on boron-doped diamond electrode for determination of the chemotherapeutic drug methotrexate in pharmaceutical and biological samples. Electroanalysis 27: 42-51. doi:10.1002/elan.201400326

Tian, H., and B. N. Cronstein. 2007. Understanding the mechanisms of action of methotrexate: implications for the treatment of rheumatoid arthritis. Bulletin of the NYU Hospital for Joint Diseases 65: 168-73.

Turci, R., G. Micoli, and C. Minoia. 2000. Determination of methotrexate in environmental samples by solid phase extraction and high performance liquid chromatography: ultraviolet or tandem mass spectrometry detection? Rapid Communication in Mass Spectrometry 14: 685-91. doi:10.1002/(sici)1097-0231(20000430)14:8<685::aidrcm937>3.0.co;2-2

van den Hoogen, F. H. J., A. M. T. Boerbooms, and L. B. A. van de Putte. 1989. Methotrexate treatment in scleroderma. The American Journal of Medicine 87: 116-117. doi:10.1016/S0002-9343(89)80499-1

Van Dooren-Greebe, R. J., A. L. A. Kuijpers, J. Mulder, T. De Boo, and P. C. M. Van De Kerkhof. 1994. Methotrexate revisited: effects of long-term treatment in psoriasis. British Journal of Dermatology 130: 204-10. doi:10.1111/ j.1365-2133.1994.tb02901.x

Wang, F., Y. Wang, L. Kui, X. Wei, and B. Ye. 2012. Sensitive determination of methotrexate at nano-Au self-assembled monolayer modified electrode. Journal of Electroanalytical Chemistry 674: 83-89. doi:10.1016/j.jelechem. 2012.04.010

Wang, F., Y. Wu, J. Liu, and B. Ye. 2009. DNA Langmuir-Blodgett modified glassy carbon electrode as voltammetric sensor for determinate of methotrexate. Electrochimica Acta 54: 1408-13. doi:10.1016/j.electacta.2008.09.027

Wang, J., P. Tuzhi, M.-S. Lin, and T. Tapia. 1986. Trace measurements of the antineoplastic agent methotrexate by adsorptive stripping voltammetry. Talanta 33: 707-12. doi:10.1016/0039-9140(86)80170-9

Ye, B.-X., S. Qu, F. Wang, and L. Li. 2005. The study of electrochemical characteristics of methotrexate. 52: 1111-16.

Yosypchuk, B., and J. Barek. 2009. Analytical applications of solid and paste amalgam electrodes. Critical Reviews in Analytical Chemistry 39: 189-203. doi:10.1080/10408340903011838

Zhu, Z., F. Wang, F. Wang, and L. Xi. 2013. Simultaneous determination of methotrexate and calcium folinate with electrochemical method based on a poly-ABSA/functionalized MWNTs composite film modified electrode. Journal of Electroanalytical Chemistry 708: 13-19. doi:10.1016/j.jelechem.2013.09.004 